\title{
Successful Treatment of Severe Carbon Monoxide Poisoning and Refractory Shock Using Extracorporeal Membrane Oxygenation
}

\author{
Krittika Teerapuncharoen MD, Nirmal S Sharma MD, Andrew B Barker MD, \\ Keith M Wille MD MSPH, and Enrique Diaz-Guzman MD
}

\begin{abstract}
Carbon monoxide ( $\mathrm{CO}$ ) is the most common cause of poisoning and poisoning-related death in the United States. It is a tasteless and odorless poisonous gas produced from incomplete combustion of hydrocarbons, such as those produced by cars and heating systems. CO rapidly binds to hemoglobin to form carboxyhemoglobin, leading to tissue hypoxia, multiple-organ failure, and cardiovascular collapse. $\mathrm{CO}$ also binds to myocardial myoglobin, preventing oxidative phosphorylation in cardiac mitochondria and resulting in cardiac ischemia or stunning and cardiogenic pulmonary edema. Treatment of $\mathrm{CO}$ poisoning is mainly supportive, and supplemental oxygen remains the cornerstone of therapy, whereas hyperbaric oxygen therapy is considered for patients with evidence of neurological and myocardial injury. Extracorporeal membrane oxygenation (ECMO) has been utilized effectively in patients with respiratory failure and hemodynamic instability, but its use has rarely been reported in patients with $\mathrm{CO}$ poisoning. We report the successful use of venoarterial ECMO in a patient with severe $\mathrm{CO}$ poisoning and multiple-organ failure. Key words: ECMO; extracorporeal membrane oxygenation; venoarterial; $C O$ poisoning; carbon monoxide. [Respir Care 2015;60(9):ee155-ee160. (C) 2015 Daedalus Enterprises]
\end{abstract}

\section{Introduction}

Carbon monoxide $(\mathrm{CO})$ is the most common cause of poisoning and poisoning-related death, resulting in $>20,000$ emergency department visits and $\sim 450$ fatalities each year in the United States. ${ }^{1} \mathrm{CO}$ is a tasteless and odorless poisonous gas produced from incomplete combustion of hydrocarbons, and it is found in combustion

Drs Teerapuncharoen, Sharma, Wille, and Diaz-Guzman are affiliated with the Division of Pulmonary, Allergy and Critical Care Medicine, Department of Medicine, and Dr Barker is affiliated with the Division of Critical Care and Perioperative Medicine, Department of Anesthesiology, University of Alabama at Birmingham, Birmingham, Alabama.

The authors have disclosed no conflicts of interest.

Dr Teerapuncharoen presented a version of this paper at the ATS 2014, held May 16-21, 2014, in San Diego, California.

Correspondence: Enrique Diaz-Guzman MD, Lung Transplant and Adult ECMO Program, University of Alabama at Birmingham, 1102 Jefferson Tower, 625 19th Street South, Birmingham, AL 35294-7410. E-mail: diaze@uab.edu.

DOI: $10.4187 /$ respcare. 03990 fumes, such as those produced by cars and trucks, small gasoline engines, stoves, lanterns, burning charcoal and wood, gas ranges, and heating systems. CO rapidly binds to hemoglobin to form carboxyhemoglobin, leading to tissue hypoxia, multiple-organ failure, and cardiovascular collapse. ${ }^{2} \mathrm{CO}$ also binds to myocardial myoglobin, preventing oxidative phosphorylation in cardiac mitochondria and resulting in cardiac ischemia or stunning and cardiogenic pulmonary edema. ${ }^{3}$ Treatment of $\mathrm{CO}$ poisoning is mainly supportive, and supplemental oxygen remains the cornerstone of therapy, whereas hyperbaric oxygen therapy is considered for patients with evidence of neurological and myocardial injury. We present a patient who developed multiple-organ failure associated with $\mathrm{CO}$ poisoning and who was successfully supported with venoarterial extracorporeal membrane oxygenation (ECMO).

\section{Case Report}

A previously healthy 38 -y-old woman was found unresponsive in a recreational vehicle while camping in the fall. She was emergently intubated, treated with oxygen $\left(\mathrm{F}_{\mathrm{IO}_{2}}\right.$ of 1.0), and transferred to a tertiary center for suspected $\mathrm{CO}$ poisoning associated with malfunction of the 
vehicle's exhaust system. The duration and intensity of $\mathrm{CO}$ exposure were not known, but the patient's husband was found dead in the same vehicle, and witnesses described them as having good health $10 \mathrm{~h}$ before discovery. Her initial vital signs showed a heart rate of 134 beats/min and blood pressure of $87 / 54 \mathrm{~mm} \mathrm{Hg}$. Laboratory results revealed severe anion gap metabolic acidosis with a serum lactate level of $7.6 \mathrm{mmol} / \mathrm{L}$ and a carboxyhemoglobin level of $13.6 \%\left(\sim 2-4 \mathrm{~h}\right.$ after being placed on $\mathrm{F}_{\mathrm{IO}_{2}}$ of 1.0). A urine drug screen, human immunodeficiency virus, alcohol, and salicylate levels were negative. The baseline blood count, chemistry profile, liver function test, and electrocardiography were normal. Brain computed tomography was negative for intracranial pathology or cerebral edema. Chest radiograph showed bilateral air space opacities. Arterial blood gas analysis showed a pH of 7.15, a $\mathrm{P}_{\mathrm{aCO}_{2}}$ of $25 \mathrm{~mm} \mathrm{Hg}$, and $\mathrm{a}_{\mathrm{aO}_{2}}$ of $73 \mathrm{~mm} \mathrm{Hg}$ at an $\mathrm{F}_{\mathrm{IO}_{2}}$ of 1.0 (Table 1). The patient received supportive care with volume control ventilation (tidal volume of $6 \mathrm{~mL} / \mathrm{kg}$ of ideal body weight) and required an increased breathing frequency (35 breaths/min), PEEP $\left(16 \mathrm{~cm} \mathrm{H}_{2} \mathrm{O}\right.$ ), and $\mathrm{F}_{\mathrm{IO}_{2}}$ of 1.0 (peak airway pressure of $42 \mathrm{~cm} \mathrm{H}_{2} \mathrm{O}$ ). Despite fluid resuscitation, she developed refractory shock, required multiple vasoactive agents, and was too unstable to be transferred to a hyperbaric chamber.

Over the next few hours, the patient developed refractory hypoxemia $\left(\mathrm{pH} 7.23, \mathrm{P}_{\mathrm{aCO}_{2}}\right.$ of $38 \mathrm{~mm} \mathrm{Hg}, \mathrm{P}_{\mathrm{aO}_{2}}$ of $54 \mathrm{~mm} \mathrm{Hg}$ with $\mathrm{F}_{\mathrm{IO}_{2}}$ of 1.0) and progressed to multipleorgan failure, including myocardial ischemia with leftventricular dysfunction (troponin level of $47 \mathrm{ng} / \mathrm{mL}$ ), metabolic acidosis (lactate level of $11 \mathrm{mmol} / \mathrm{L}$ ), cardiogenic pulmonary edema, rhabdomyolysis (creatine kinase level of 2,887 units/L, peak at $6 \mathrm{~h}$ after presentation), severe coagulopathy (prothrombin time of $36.4 \mathrm{~s}$, international normalized ratio of 3.97, prothrombin time of $60 \mathrm{~s}$, fibrinogen level of $153 \mathrm{mg} / \mathrm{dL}$ ), acute renal failure, and liver failure. The patient was hemodynamically unstable (blood pressure of $87 / 53 \mathrm{~mm} \mathrm{Hg}$, mean arterial pressure of $64 \mathrm{~mm} \mathrm{Hg}$, heart rate of 144 beats/min) and required 5 vasopressors and an inotropic medication: norepinephrine (40 $\mu \mathrm{g} / \mathrm{min})$, vasopressin $(0.03 \mathrm{units} / \mathrm{min})$, epinephrine ( $2 \mu \mathrm{g} / \mathrm{kg} / \mathrm{min})$, phenylephrine $(300 \mu \mathrm{g} / \mathrm{min})$, dopamine $(20 \mu \mathrm{g} / \mathrm{kg} / \mathrm{min})$, and dobutamine $(10 \mu \mathrm{g} / \mathrm{kg} / \mathrm{min})$. The patient was then started on venoarterial ECMO; a bedside vascular cannulation was accomplished by an ultrasoundguided percutaneous introduction of a wire-reinforced cannula into the left femoral artery (19 French arterial cannula, Bio-Medicus, Medtronic, Minneapolis, Minnesota) and the right femoral vein (25 French multiple-side-port venous cannula, Bio-Medicus, Medtronic). The placement of the venous cannula at the level of the right atrium was confirmed by chest radiograph (Fig. 1). The draining line (venous cannula) was connected to a heparin-coated, hollow-fiber membrane oxygenator (Quadrox-i, Maquet,
Wayne, New Jersey), which was powered by a portable heart-lung centrifugal pump (Cardiohelp, Maquet). After ECMO initiation, there was a gradual improvement in hemodynamics, lactic acidosis, and oxygenation. The patient was weaned from norepinephrine, vasopressin, and phenylephrine. Mechanical ventilation settings were reduced to facilitate lung-protective ventilation (breathing frequency of 18 breaths/min, PEEP of $8 \mathrm{~cm} \mathrm{H}_{2} \mathrm{O}$, peak airway pressure of $28 \mathrm{~cm} \mathrm{H}_{2} \mathrm{O}$ ). Chest radiograph showed diffuse alveolar opacities (Fig. 1), and chest computed tomography showed patchy, multifocal lung consolidation with interstitial edema and small bilateral pleural effusions (Fig. 2). An echocardiogram showed global myocardial dysfunction with an estimated left-ventricular ejection fraction of $<20 \%$. On day 2 of ECMO support, an intra-aortic balloon pump was deployed to support cardiac function and prevent left-ventricular distention, and dialysis was initiated to manage volume overload and worsening uremia. Systemic heparinization was monitored and adjusted based on thrombelastography, activated clotting time, and anti-factor Xa activity. The pulse, color, and warmth of the lower extremities, cerebral saturation, and blood gases from the right radial artery were monitored routinely, and there were no signs of lower-limb ischemia or cerebral hypoxia. On day 4, a repeat echocardiogram showed significant improvement in cardiac function (left-ventricular ejection fraction of $>55 \%$ ); therefore, the intra-aortic balloon pump was removed, and venoarterial ECMO was discontinued. Her oxygenation, hemodynamics, and kidney function improved gradually, and all supportive therapies (inhaled nitric oxide, vasopressors, continuous renal replacement therapy) were discontinued. The patient regained consciousness without neurological deficits. During the following weeks, she participated in physical rehabilitation and was able to ambulate independently. She was weaned from oxygen and discharged home $30 \mathrm{~d}$ after admission. Follow-up studies at 6 weeks after hospital discharge showed a small left-sided pleural effusion with normal lung parenchyma (Fig. 3). The patient was seen at 12 and 24 weeks and had normal lung function tests.

\section{Discussion}

Compared with $\mathrm{O}_{2}$, CO has greater binding affinity for hemoglobin, myoglobin, and cytochrome, resulting in cellular hypoxia and lactic acidosis. The affinity of $\mathrm{CO}$ for hemoglobin is 210 times greater than that of $\mathrm{O}_{2}{ }^{2}$ The half-life of CO is reduced to $49-99$ min with $100 \% \mathrm{O}_{2}$ at atmospheric pressure. ${ }^{4}$ Pulse oximetry and arterial blood gases overestimate and poorly correlate with $\mathrm{P}_{\mathrm{aO}_{2}}$ in patients with severe $\mathrm{CO}$ poisoning. Pulse oximetry cannot detect carboxyhemoglobin, and measurement of $\mathrm{P}_{\mathrm{aO}_{2}}$ from arterial blood gas tends to be normal because $\mathrm{P}_{a O_{2}}$ reflects $\mathrm{O}_{2}$ dissolved in blood (not affected by $\mathrm{CO}$ ). In contrast, 
Use of ECMO In Severe CO PoIsoning

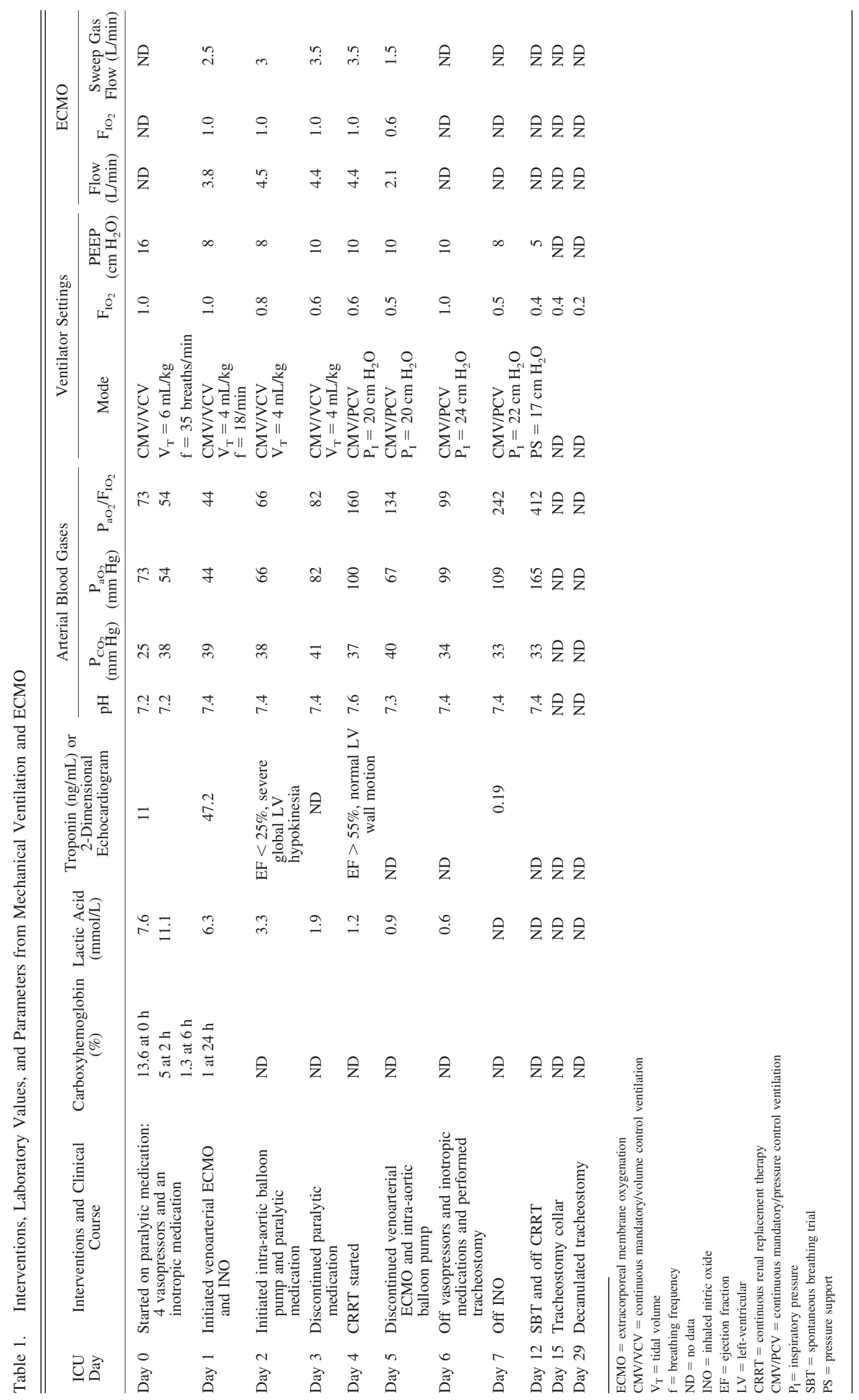


hemoglobin-bound $\mathrm{O}_{2}$ or oxyhemoglobin, which normally composes $98 \%$ of $\mathrm{P}_{\mathrm{aO}_{2}}$ content, is profoundly reduced in the presence of carboxyhemoglobin. At present, accurate assessment of $\mathrm{P}_{\mathrm{aO}_{2}}$ content in $\mathrm{CO}$ poisoning can be performed only by analysis of arterial blood by CO-oximetry. ${ }^{5}$ Although noninvasive carboxyhemoglobin detection is possible today with multi-wavelength pulse-technology, accuracy is somewhat limited by hypoxemia. ${ }^{6}$

In the presence of carboxyhemoglobin, the oxyhemoglobin dissociation curve shifts to the left and further impairs tissue $\mathrm{O}_{2}$ delivery, leading to cellular hypoxia. $\mathrm{CO}$ also interferes with peripheral oxygen utilization by binding to extravascular molecules such as myoglobin, cytochromes, and reduced nicotinamide adenine dinucleotide phosphate hydrogen reductase, resulting in impairment of oxidative phosphorylation in mitochondria. These mechanisms lead to cellular acidosis and may result in cardio-

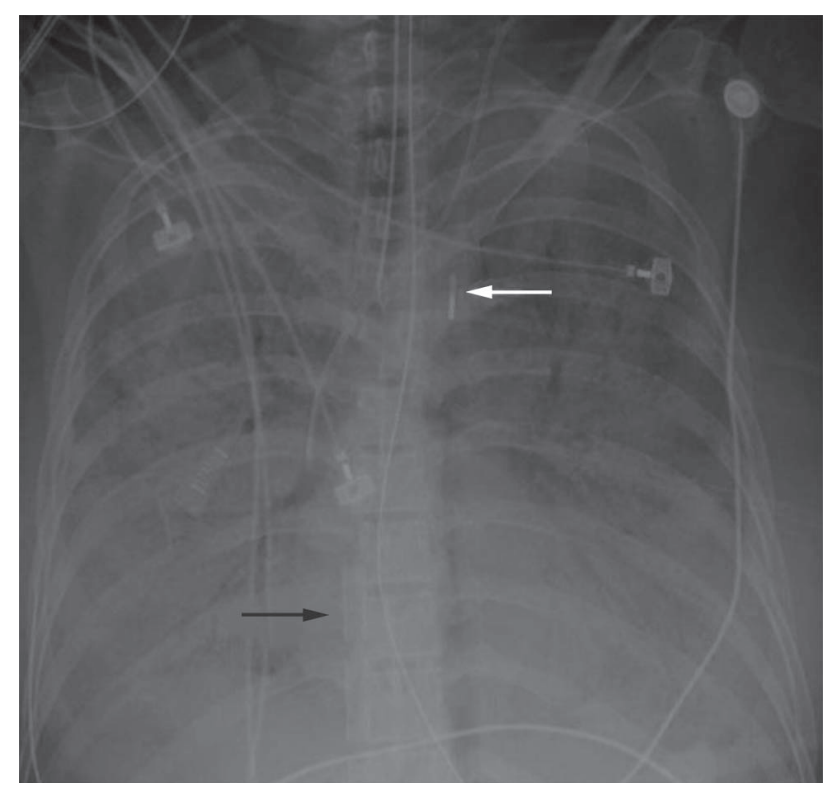

Fig. 1. Chest radiograph showing diffuse opacities. The tip of the intra-aortic balloon pump is seen above the left main bronchus (white arrow). The ECMO venous cannula terminates at the right atrium (black arrow). vascular collapse, noncardiogenic pulmonary edema, and multiple-organ failure. ${ }^{2}$

Myocardial ischemia or stunning was previously described in a patient with $\mathrm{CO}$ poisoning and heart failure with normal coronary arteries. Myocardial damage is caused by impairment of oxygen utilization rather than by absence of oxygen supply. $\mathrm{CO}$ prevents mitochondrial $\mathrm{O}_{2}$ utilization by oxidative phosphorylation in myocardial myoglobin, resulting in cardiac ischemia or stunning and leading to heart failure and pulmonary edema. Myocardial stunning is a reversible process, although the half-life of $\mathrm{CO}$ that binds to myoglobin is unknown but is thought to be longer than that of carboxyhemoglobin., 3 The presence of severe myocardial ischemia in patients with $\mathrm{CO}$ poisoning should prompt clinicians to consider the need for left-heart catheterization to rule out concomitant coronary artery disease.

Supplemental 100\% oxygen remains the cornerstone of therapy for $\mathrm{CO}$ poisoning. Hyperbaric oxygen therapy has been traditionally used in patients with evidence of neurological or myocardial injury from $\mathrm{CO}$ poisoning. Hyperbaric therapy increases dissolved $\mathrm{O}_{2}$ content in blood and accelerates elimination of $\mathrm{CO}^{8}$ Similarly, ECMO results in delivery of super-oxygenated blood (frequently $\mathrm{P}_{\mathrm{aO}_{2}}$ of $300-500 \mathrm{~mm} \mathrm{Hg}$ ) to the native circulation, effectively reducing carboxyhemoglobin levels. ${ }^{9}$ The unstable clinical status of our patient did not allow her to receive hyperbaric oxygen therapy. It is worth mentioning that many patients with severe CO poisoning develop delayed encephalopathy and cognitive sequelae even after 4 weeks of conventional hyperbaric oxygen therapy. ${ }^{10}$ Our patient was followed for $\sim 6$ months and never reported clinical symptoms of encephalopathy.

To our knowledge, the use of venoarterial ECMO for management of $\mathrm{CO}$ poisoning has not been reported previously. We performed a review of the literature using the PubMed and Embase databases, restricting our search to the words ECMO and carbon monoxide, and found only one report of ECMO use in a patient with severe CO poisoning who was supported with venovenous ECMO for

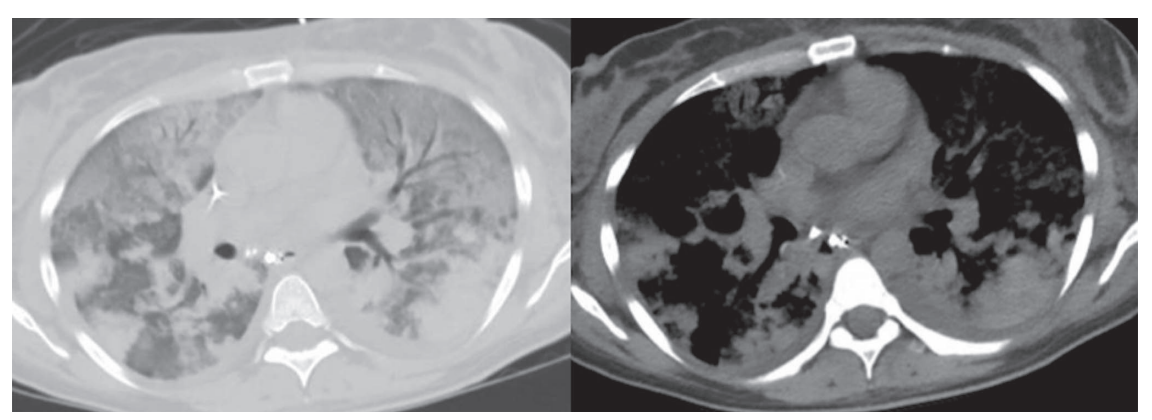

Fig. 2. Chest computed tomography on day 5 showed patchy, multifocal lung consolidation with interstitial edema and small bilateral pleural effusions. 


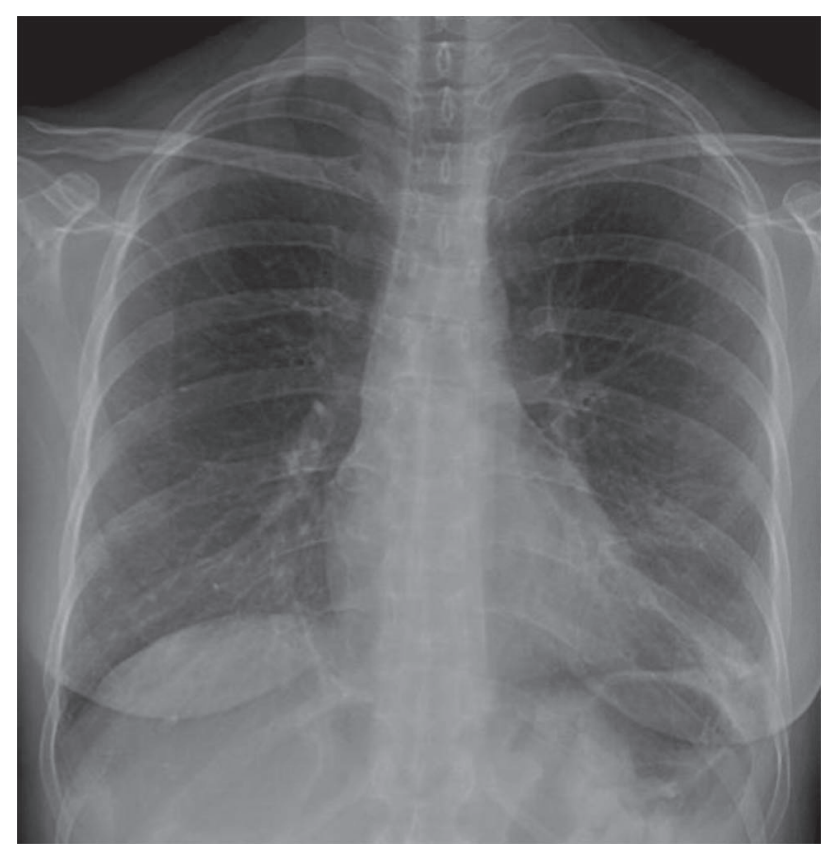

Fig. 3. Chest radiograph at 6 weeks after hospital discharge showed markedly improved consolidation and a residual left-sided pleural effusion.

$7 \mathrm{~d}$ and made a full recovery. ${ }^{11}$ ECMO use has also been reported in patients with respiratory failure secondary to inhalational injuries. For example, Kornberger et al ${ }^{12}$ reported a patient with respiratory failure secondary to smoke inhalation injury who was treated by removal of extracorporeal $\mathrm{CO}_{2}$. Similarly, Patton et al ${ }^{13}$ described a patient with ARDS secondary to thermal burn and inhalational injury who was supported with venovenous ECMO.

For our patient, venoarterial ECMO was chosen over venovenous ECMO due to the presence of cardiogenic shock. Venoarterial ECMO reduced cardiac oxygen consumption and provided both hemodynamic and respiratory support ${ }^{14}$ as a bridge to recovery in this critically ill patient. Peripheral venoarterial ECMO with femoral and subclavian (or axillary) artery access can be achieved either percutaneously or via an open-surgery approach. Femoralfemoral venoarterial ECMO results in distal retrograde flow and carries the risk of cerebral and coronary hypoperfusion due to competition with anterograde cardiac output ejected from the left ventricle. The mixing point between deoxygenated blood from the left ventricle and oxygenated blood from the ECMO circuit is frequently located at the base of the aortic root, but varies in location depending on the native ejection fraction and ECMO flow. ${ }^{14}$ Poor lung function with good myocardial function may result in upper-body hypoxemia. In comparison, axillary artery cannulation results in antegrade aortic flow and is preferred for patients with preserved left-ventricular function. ${ }^{15}$ Compared with femoral percutaneous cannulation, the axillary approach usually requires surgical dissection and is more time-consuming. In our patient, femoral artery access was chosen due to severe hemodynamic instability and need for rapid deployment of ECMO. ${ }^{14}$ We monitored arterial blood gases from the right radial artery and cutaneous cerebral pulse oximetry to detect upper-body hypoxemia. Concomitant use of an intra-aortic balloon pump improved coronary perfusion with balloon inflation during diastole. ${ }^{14}$ Another downside of femoral access is ipsilateral lower-extremity ischemia in an arterial-cannulated leg or venous obstruction in a venous-cannulated leg, which can be detected by serial monitoring of lower-extremity pulses and watching for signs of leg ischemia or edema such as swelling, color, and warmth. ${ }^{14}$ Our patient did not have a problem with venous obstruction or lowerlimb ischemia and did not require insertion of a distal perfusion catheter.

Our case adds to the limited available literature showing that venoarterial ECMO can also support patients with severe $\mathrm{CO}$ poisoning and should be considered for those with severe hemodynamic compromise. In conclusion, ECMO can be safely and effectively used to support patients with refractory hypoxemia associated with severe CO poisoning. Treatment with ECMO should be considered for patients with $\mathrm{CO}$ poisoning who deteriorate despite mechanical ventilation support, particularly when hyperbaric oxygen therapy is not available. Venovenous ECMO has been used in patients with $\mathrm{CO}$ poisoning and respiratory failure, but venoarterial ECMO is preferred in patients with cardiogenic shock and hemodynamic instability.

\section{REFERENCES}

1. Centers for Disease Control and Prevention (CDC). Nonfatal, unintentional, non-fire-related carbon monoxide exposures-United States, 2004-2006. MMWR Morb Mortal Wkly Rep 2008;57(33): 896-899.

2. Prockop LD, Chichkova RI. Carbon monoxide intoxication: an updated review. J Neurol Sci 2007;262(1-2):122-130.

3. Tritapepe L, Macchiarelli G, Rocco M, Scopinaro F, Schillaci O, Martuscelli E, Motta PM. Functional and ultrastructural evidence of myocardial stunning after acute carbon monoxide poisoning. Crit Care Med 1998;26(4):797-801.

4. Weaver LK, Howe S, Hopkins R, Chan KJ. Carboxyhemoglobin half-life in carbon monoxide-poisoned patients treated with $100 \%$ oxygen at atmospheric pressure. Chest 2000;117(3):801-808.

5. Hampson NB. Pulse oximetry in severe carbon monoxide poisoning. Chest 1998;114(4):1036-1041.

6. Feiner JR, Rollins MD, Sall JW, Eilers H, Au P, Bickler PE. Accuracy of carboxyhemoglobin detection by pulse CO-oximetry during hypoxemia. Anesth Analg 2013;117(4):847-858.

7. Gandini C, Castoldi AF, Candura SM, Locatelli C, Butera R, Priori S, Manzo L. Carbon monoxide cardiotoxicity. J Toxicol Clin Toxicol 2001;39(1):35-44. 


\section{Use of ECMO In Severe CO PoIsoning}

8. Weaver LK, Hopkins RO, Chan KJ, Churchill S, Elliott CG, Clemmer TP, et al. Hyperbaric oxygen for acute carbon monoxide poisoning. N Engl J Med 2002;347(14):1057-1067.

9. Yin L, Cai Q, Zhen Q, Chen Z, Li F, Yan P, et al. Treatment of acute carbon monoxide poisoning with extracorporeal membrane trioxygenation. Int J Artif Organs 2012;35(12):1070-1076.

10. Kwon OY, Chung SP, Ha YR, Yoo IS, Kim SW. Delayed postanoxic encephalopathy after carbon monoxide poisoning. Emerg Med J 2004; 21(2):250-251.

11. McCunn M, Reynolds HN, Cottingham CA, Scalea TM, Habashi NM. Extracorporeal support in an adult with severe carbon monoxide poisoning and shock following smoke inhalation: a case report. Perfusion 2000;15(2):169-173.
12. Kornberger E, Mair P, Oswald E, Hörmann C, Ohler K, Balogh D. Inhalation injury treated with extracorporeal $\mathrm{CO}_{2}$ elimination. Burns 1997;23(4):354-359.

13. Patton ML, Simone MR, Kraut JD, Anderson HL 3rd, Haith LR Jr. Successful utilization of ECMO to treat an adult burn patient with ARDS. Burns 1998;24(6):566-568.

14. Chung M, Shiloh AL, Carlese A. Monitoring of the adult patient on venoarterial extracorporeal membrane oxygenation. ScientificWorldJournal 2014;2014:393258.

15. Roussel A, Al-Attar N, Khaliel F, Alkhoder S, Raffoul R, Alfayyadh $\mathrm{F}$, et al. Arterial vascular complications in peripheral extracorporeal membrane oxygenation support: a review of techniques and outcomes. Future Cardiol 2013;9(4):489-495. 